\title{
Is the Histopathological Subtype Important for Tumor Response to Irradiation in non-metastatic Esophageal Cancer?
}

\author{
XENIA ELENA BACINSCHI ${ }^{1,2}$, RODICA MARICELA ANGHEL ${ }^{1,2}$, \\ MONICA IRINA STANUICA ${ }^{3}$, INGA SAFTA ${ }^{4}$, ALINA PAUNESCU ${ }^{* *}$, \\ MONICA MARILENA TANTU ${ }^{5}$, ALIS ILIE ${ }^{6}$, SILVIA MIHAELA ILIE ${ }^{7}$ \\ ${ }^{1}$ Institute of Oncology Prof Dr Alexandru Trestioreanu, Department of Oncology-Radiotherapy, 252 Fundeni Str., 022328, \\ Bucharest, Romania \\ 2.University of Medicine and Pharmacy Carol Davila, 8 Eroii Sanitari Blvd., 050474, Bucharest, Romania \\ ${ }^{3}$ Institute of Oncology Prof. Dr. Alexandru Trestioreanu, Department of Radiotherapy II, 252 Fundeni Str., 022328, \\ Bucharest, Romania \\ ${ }^{4}$ Department of Medical Oncology, Antoine Lacassagne Cancer Center, 33 Avenue de Valombrose, 06100, Nice, France \\ ${ }^{5}$ University of Pitesti, Faculty of Sciences, Physical Education and Informatics, 2 Targu din Vale Str., 110040, Pitesti, \\ Romania \\ ${ }^{6}$ Cancer Biology Transfer Platform, Georges Francois Leclerc Cancer Center, 1 Rue du Professeur Marion, 21000, Dijon, \\ France \\ ${ }^{7}$ Department of Medical Oncology, Georges Francois Leclerc Cancer Center, 1 Rue du Professeur Marion, 21000, Dijon, \\ France
}

\begin{abstract}
Esophageal cancer is still a health problem in middle income countries. The up-front treatment in localized disease is crucial for a better survival. Data from literature are in favor of a better response to radiotherapy of squamous histology. We have run a retrospective study to compare the response of histological subtypes of esophageal cancer to radiotherapy according to irradiation. Of 44 cases (53.7\%) of squamous cell localized esophageal carcinoma and 38 (46.3\%) of adenocarcinoma, the response after radiotherapy containing multimodal neoadjuvant treatment was $29.5 \%$ (13pts) versus $39.5 \%$ (15pts) $(p=0.475)$. No correlation was found between histology and tumor shrinkage. Survival was found similar between the two subgroups. Indeed, median relapse free survival was 11 months for both groups with 95\% CI [8.86-13.13] or 95\% CI [4.526-17.47], log rank 0.394 and median overall survival was 12 months, 95\% CI [9.44-14.55] in squamous versus 15 months, 95\% [8.30-21.69] in adenocarcinoma cases, log rank 0.195. In univariate regression, the median relapse free survival was significantly associated with irradiation dose and the concomitance of chemotherapy to radiotherapy, while in multivariate analysis only the last variable remained significant: HR 0.425, 95\% CI [0.225-0.806], $p=0.009$. Our analysis showed a tendency to a better response in adenocarcinoma esophageal cancer after multimodal radiotherapy containing treatment.
\end{abstract}

Keywords: radiotherapy, esophageal cancer, histopathological subtype, squamous cell

\section{Introduction}

Esophageal cancer incidence worldwide and in Europe is quite heterogeneous, representing a major health problem in middle-income countries where the prognosis remains poor, as it is the $6^{\text {th }}$ cause of cancer related death [1]. The two most important subtypes according to cancer tissue histology are squamous and adenocarcinoma tumors, which present a different prognosis and differ in terms of response to multimodal treatment. European and American guidelines distinguish different treatment algorithms for early stage squamous or adeno esophageal carcinomas [2]. Concerning squamous carcinoma (SCC), an indication for up-front irradiation concomitant with chemotherapy is recommended, while for adenocarcinoma (AC) the place of radiotherapy is sequential [3].

This is based on the differences seen in preclinical phases concerning the sensitivity to irradiation and on several analyses showing differences in terms of clinical or histopathological response to radiotherapy, with a much higher responsiveness of the squamous histology [4-6]. 
Nevertheless, several studies showed no difference between the responses to radiation, in the two histological subtypes [7-8].

We questioned, in our middle-income country university cancer center, whether there were differences in terms of esophageal tumor response to irradiation according to the histological type, regardless chemotherapy regimen, concomitant or sequential, and backbone chemotherapy regimen and whether there was an impact on survival.

\section{Materials and methods}

Medical files of patients with non-metastatic invasive adenocarcinoma (AC) or squamous cell carcinoma (SCC) diagnosis, addressed to Institute of Oncology Prof Dr. Alexandru Trestioreanu Bucharest between 2009 and 2017 for up-front radio-chemotherapy (CRT) or radiotherapy and sequential chemotherapy as first intention treatment were analyzed. The main inclusion criteria were age $>18$ years, clinical stage cT1-3N1-3M0 following AJCC $7^{\text {th }}$ edition [9]. Patients were excluded if they had one of the following: up-front surgery, irradiation for palliative purposes, metachronous cancer or severe comorbidities.

All patients underwent a radiological and endoscopic evaluation 4-6 weeks following primary treatment and were operated if they were eligible, according to RECIST 1.1 criteria and non RECIST criteria (for endoscopic evaluation or TDM evaluation whenever RECIST 1.1 non applicable) were used for response assessments [10].

The primary objective was to determine whether there were differences between the response rates following up-front irradiation containing oncological treatment in patients of two histological subgroups. The secondary objective was to identify if there were any differences in terms of survival and in terms of tolerance to treatment.

Data were analyzed using SPPS statistics version 23 (IBM Corporation, Armonk, NY, USA). The measurable outcomes were the response rate in the two subgroups and the secondary outcomes were median relapse free survival and median overall survival according to histology, time frame from inclusion until the first occurrence of local, regional, or distant disease recurrence of invasive disease, the rate and duration of grade III-IV adverse events (AE)according to CTCAE v. 4.03 during radiotherapy till the first medical visit and 6 months after the end of radiotherapy [11].

To compare the subgroups, non-parametric tests were employed, the chi-squared test determined the correlation between tumor response and histopathological subtype and other clinical and treatment variables, and logistic regression was used to find if relapse was predicted based on these correlations. Fisher's exact test was employed when there were fewer than five cases in any cell of the $2 \times 2$ table. Association between variables and survival was analyzed using Cox proportional hazard regression analysis and survival curves were generated using the Kaplan-Meier method and compared using the log-rank test. HRs and 95\% CIs for variables were calculated using the Cox proportional hazard model. All statistical tests were two-sided, and a p-value $<0.05$ was considered to be significant.

\section{Results and discussions}

\subsection{Results}

Of 82 cases retained for analysis, $44(53.7 \%)$ were SCC and $38(46.3 \%)$ were AC. The median age was 62 years old range 41-85. The large majority of patients, $89 \%$ (77pts) were under 75 years old and most patients had a performance status ECOG 0-1 81.7\% (67 pts). In the majority of cases, the lower and the gastro-esophageal junction were involved, 63.4\% (52pts). The upper third of esophagus was involved in a reduced fraction of patients, $9.8 \%$ (8pts) and the middle esophagus in $26.8 \%$ (22pts) of cases.

The tumor grade was 2 in $46 \%$ (23pts) and 3 in 36\% (18 pts), the tumor clinical stage $1-3$ in $70.1 \%$ (54 pts), while the stage N1-2 was registered in $67.5 \%$ (52pts), in total cTNM stage was I in $27.3 \%$ (21pts), II in $37.7 \%$ (29pts), III in $35.1 \%$ (27pts). 
Most patients had a personal history of chronic alcohol and smoking consumption $(67.9 \%$, 53pts respectively 59\%, 46pts), 57.3\% (47pts) presented grade II-IV dysphagia and 50\% (41pts) developed grade II or III denutrition. Regarding treatment, $20.7 \%$ (17pts) received concomitant radio-chemotherapy while $75.6 \%$ (62pts) of sequential treatment. The median recommended dose was 47.5 Gy and the median administrated dose was $45.8 \mathrm{~Gy}$, range 30-66.6Gy with $91.5 \%$ (75 pts) being irradiated on the tumor and regional lymph-nodes fields.

The cytotoxic regimens used were either 5-fluorouracyl (37pts, 45.2\%) either paclitaxel (25 pts, $30.5 \%$ ) based, both containing a platinum agent (cisplatin or carboplatin) (Tabel 1).

Table 1. Patient characteristics in the two subgroups SCC and AC of esophageal cancer patients

\begin{tabular}{|c|c|c|c|c|c|}
\hline Variable/population & SCC & & ADK & & p-value \\
\hline & No44 & $\%(53.7)$ & No38 & $\%(46.3)$ & \\
\hline $\begin{array}{c}\text { Age } \\
<75 \text { years } \\
>75 \text { years }\end{array}$ & $\begin{array}{c}41 \\
3\end{array}$ & $\begin{array}{c}93.2 \\
6.8\end{array}$ & $\begin{array}{c}32 \\
6\end{array}$ & $\begin{array}{c}84.2 \\
15 .\end{array}$ & 0.195 \\
\hline $\begin{array}{c}\text { Toxics } \\
\text { Smoking } \\
\text { Alcohol }\end{array}$ & $\begin{array}{l}34 \\
21\end{array}$ & $\begin{array}{l}77.3 \\
47.7\end{array}$ & $\begin{array}{l}19 \\
25\end{array}$ & $\begin{array}{l}50 \\
68\end{array}$ & 0.033 \\
\hline $\begin{array}{c}\text { Performance status } \\
\text { ECOG 0-1 } \\
\text { ECOG } 2\end{array}$ & $\begin{array}{l}34 \\
10\end{array}$ & $\begin{array}{l}77.3 \\
22.7\end{array}$ & $\begin{array}{c}33 \\
5\end{array}$ & $\begin{array}{l}86.8 \\
13.2\end{array}$ & 0.246 \\
\hline $\begin{array}{l}\text { Tumor site } \\
\text { upper third } \\
\text { middle } \\
\text { lower+ GOJ }\end{array}$ & $\begin{array}{c}8 \\
19 \\
17\end{array}$ & $\begin{array}{l}18.2 \\
43.2 \\
38.6\end{array}$ & $\begin{array}{c}0 \\
3 \\
35\end{array}$ & $\begin{array}{c}0 \\
7.9 \\
92.1\end{array}$ & $<0.0001$ \\
\hline $\begin{array}{c}\text { Grading } \\
1 \\
2 \\
3 \\
\end{array}$ & $\begin{array}{c}5 \\
13 \\
8 \\
\end{array}$ & $\begin{array}{l}11.4 \\
29.5 \\
18.2 \\
\end{array}$ & $\begin{array}{c}4 \\
10 \\
10\end{array}$ & $\begin{array}{l}10.5 \\
26.3 \\
26.3 \\
\end{array}$ & 0.852 \\
\hline $\begin{array}{c}\text { Clinical tumor stage } \\
\text { cT1-3 } \\
\text { cT4a-b }\end{array}$ & $\begin{array}{l}27 \\
13 \\
\end{array}$ & $\begin{array}{l}61.4 \\
29.5\end{array}$ & $\begin{array}{l}27 \\
10 \\
\end{array}$ & $\begin{array}{l}71.1 \\
26.3 \\
\end{array}$ & 0.414 \\
\hline $\begin{array}{c}\text { Clinical nodal stage } \\
\text { cN0 } \\
\text { cN1-2 } \\
\text { cN3 }\end{array}$ & $\begin{array}{c}10 \\
26 \\
4\end{array}$ & $\begin{array}{c}22.7 \\
59.1 \\
9.1\end{array}$ & $\begin{array}{c}7 \\
26 \\
4\end{array}$ & $\begin{array}{l}18.4 \\
68.4 \\
10.5\end{array}$ & 0.593 \\
\hline $\begin{array}{c}\text { Clinical TNM stage } \\
\text { I } \\
\text { II } \\
\text { III } \\
\end{array}$ & $\begin{array}{l}13 \\
14 \\
13 \\
\end{array}$ & $\begin{array}{l}29.5 \\
31.8 \\
29.5 \\
\end{array}$ & $\begin{array}{c}8 \\
15 \\
14 \\
\end{array}$ & $\begin{array}{l}21.1 \\
39.5 \\
36.8 \\
\end{array}$ & 0.451 \\
\hline $\begin{array}{c}\text { Clinical presentation } \\
\text { Dysphagia } \\
\text { Denutrition }\end{array}$ & $\begin{array}{l}21 \\
18\end{array}$ & $\begin{array}{l}47.7 \\
40.9\end{array}$ & $\begin{array}{l}20 \\
23\end{array}$ & $\begin{array}{l}52.6 \\
60.5\end{array}$ & $\begin{array}{l}0.920 \\
0.076\end{array}$ \\
\hline $\begin{array}{c}\text { Field of irradiation } \\
\text { Tumor } \\
\text { Tumor+ lymph nodes }\end{array}$ & $\begin{array}{c}2 \\
42\end{array}$ & $\begin{array}{c}4.6 \\
95.4\end{array}$ & $\begin{array}{c}5 \\
33\end{array}$ & $\begin{array}{l}13.2 \\
86.8\end{array}$ & 0.164 \\
\hline $\begin{array}{l}\text { RT dose } \\
\leq 45 \mathrm{~Gy} \\
>45 \mathrm{~Gy}\end{array}$ & $\begin{array}{l}24 \\
20\end{array}$ & $\begin{array}{l}45.5 \\
54.5\end{array}$ & $\begin{array}{l}20 \\
18 \\
\end{array}$ & $\begin{array}{l}52.6 \\
47.4\end{array}$ & 0.862 \\
\hline $\begin{array}{c}\text { Concurrent CHT } \\
\text { No CHT } \\
\text { 5FU-CDDP } \\
\text { PTX-CBDCA }\end{array}$ & $\begin{array}{l}32 \\
10 \\
2\end{array}$ & $\begin{array}{c}72.7 \\
22.7 \\
4.5 \\
\end{array}$ & $\begin{array}{c}30 \\
5 \\
3 \\
\end{array}$ & $\begin{array}{c}78.9 \\
13.2 \\
7.9 \\
\end{array}$ & 0.302 \\
\hline $\begin{array}{l}\text { Sequential CHT } \\
\text { 5FU-CDDP } \\
\text { PTX-CBDCA }\end{array}$ & $\begin{array}{c}17 \\
7\end{array}$ & $\begin{array}{l}70.8 \\
29.2\end{array}$ & $\begin{array}{c}5 \\
13\end{array}$ & $\begin{array}{l}27.7 \\
72.3\end{array}$ & 0.062 \\
\hline $\begin{array}{c}\text { Response(non-RECIST) } \\
\text { Yes } \\
\text { No }\end{array}$ & $\begin{array}{c}13 \\
9\end{array}$ & $\begin{array}{l}29.5 \\
20.5\end{array}$ & $\begin{array}{c}15 \\
9\end{array}$ & $\begin{array}{l}39.5 \\
23.7\end{array}$ & 0.475 \\
\hline
\end{tabular}

ECOG= Performance Status, GOJ=gastroesophageal junction, cT=tumor stage, cN=lymph node stage, Gy=grays, $\mathrm{CHT}=$ chemotherapy, 5FU-CDDP=5-fluorouracil $(\mathrm{FU})+\mathrm{CDDP}$ regimen, $\mathrm{PTX}-\mathrm{CBDCA}=$ paclitaxel+carboplatin regimen, RECIST $=$ Response evaluation criteria in solid tumors. 
Average number of cycles was 2.92 for 5-fluorouracyl-platinum regimen and 2.5 for paclitaxelplatinum regimen. The median density dose was $83.78 \%$ range 57-100 and 93.75\% range 90-100 $(\mathrm{p}=0.07)$, respectively.

Regarding subgroup analysis in patients with SCC, the median number of chemotherapy cycles was 2.92 range 1-7, while in $\mathrm{AC}$ was 3.21 range $1-6(\mathrm{p}=0.02)$.

The average density dose was $81.88 \%$, range $57-100$ in SCC patients while in AC patients was $93.10 \%$ range $73-98(\mathrm{p}=0.03)$.

The tolerance was marked by grade III-IV toxicities in 18 SCC patients (27.3\%) and in 23 AC patients $(60.5 \%)$, of which 12 cases $(48 \%)$ of grade III-IV neutropenia respectively 13 cases $(52 \%)$ $(\mathrm{p}=0.496)$. The average number of episodes of grade III-IV toxicities was 1.84 range (1-4) respectively 2.15 range $(1-3)(\mathrm{p}=0.441)$.

The non- RECIST response defined either by any recorded tumor regression by CT-scan or by radiology and endoscopy were registered in 28 patients of which 13 with SCC and 15 with AC (Table 1). RECIST assessment was applicable only in 3 patients and was therefore not recorded.

The response was directly and significantly correlated only with the field of irradiation, tumor and regional lymph nodes versus only tumor site $(\mathrm{p}=0.025)$.

For a median follow up of 14 months range 2-101 months, in SCC patients relapse was recorded in 12 cases $(22.7 \%)$, similarly to what it was observed in AC patients, 11 cases $(28.9 \%)(\mathrm{p}=0.344)$. The relapse was locoregional in 5pts $(41.6 \%)$, in lymph nodes or in bones in 5 cases $(41.6 \%)$ and visceral (liver, lung) in 2 cases (16.6\%) respectively 1 case (9.1\%), 3 cases $(27.3 \%)$ and 7 cases $(63.4 \%)$ $(\mathrm{p}=0.052)$. Relapse was directly correlated with clinical tumor stage $(\mathrm{p}=0.02)$ and with the type of concomitant chemotherapy, taxane-platinum regimen versus 5FU-platinum regimen $(\mathrm{p}=0.037)$.

The median time till relapse was 11 months and the median time of survival after relapse was 24 weeks (range 4 to 104 weeks).

Treatment upon relapse was chemotherapy in 5 pts $(41.6 \%)$ versus 8 pts $(72.7 \%)$, re-irradiation in 4 pts $(33.3 \%)$ versus 2 pts $(18.2 \%)$ and surgery in 2 cases $(16.6 \%)$ from the SCC group ( $=0.378)$.

In the whole population, general median relapse free survival (RFS) and median overall survival (OS) were 11 months 95\% CI [8.70-13.29] and 14 months 95\% CI [11.71-16.28], respectively.

No differences were recorded in median relapse free survival, which was 11 months in both subgroups 95\% CI [8.86-13.13] and 95\% CI [4.526-17.47], log rank 0.394, nor in median overall survival; 12 months in SCC 95\% CI[9.44-14.55] versus 15 months in AC 95\% [8.30-21.69], log rank 0.195 (Figure 1).
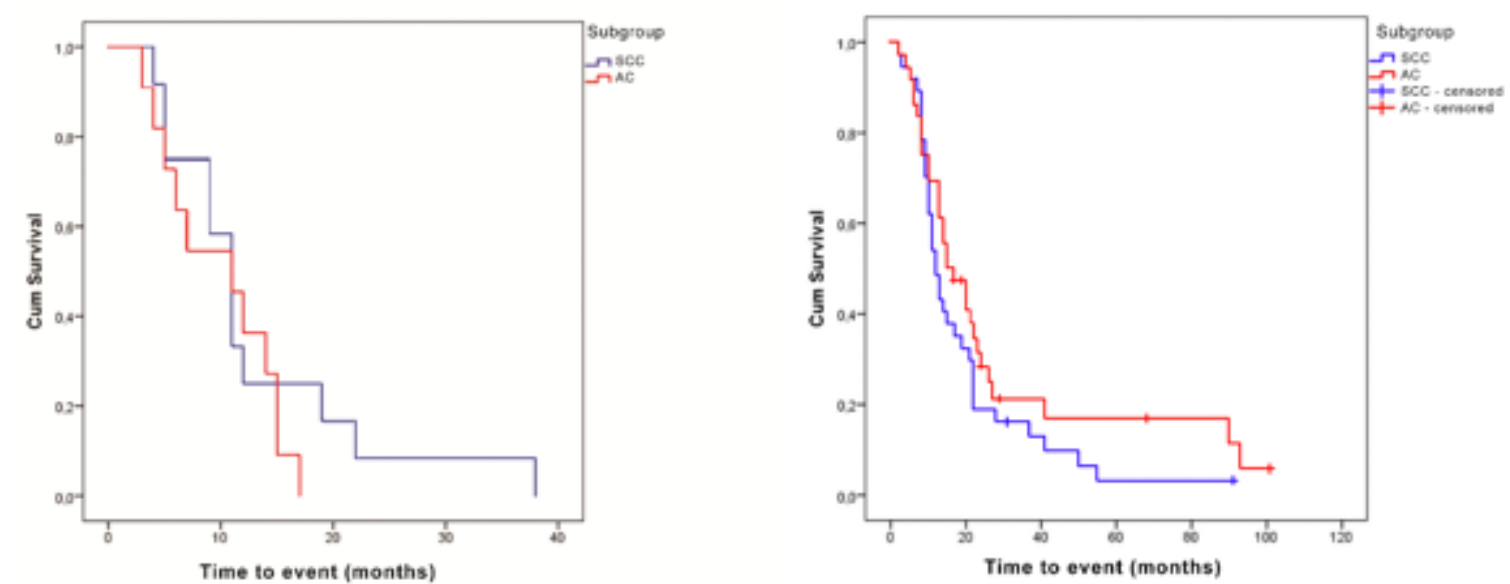

Figure 1. Kaplan-Meier relapse-free survival (right) and overall survival (left) curves according to esophageal cancer histopathological subtype 
The median OS was 15 months, 95\% CI [10.96-19.03] in patients with progressive disease versus 23 months, 95\% CI [18.38-27.61] for those with a partial response or a stable disease according to non RECIST criteria, following the up-front treatment, log rank $\mathrm{p}$ value $<0.05$ (Figure 2).

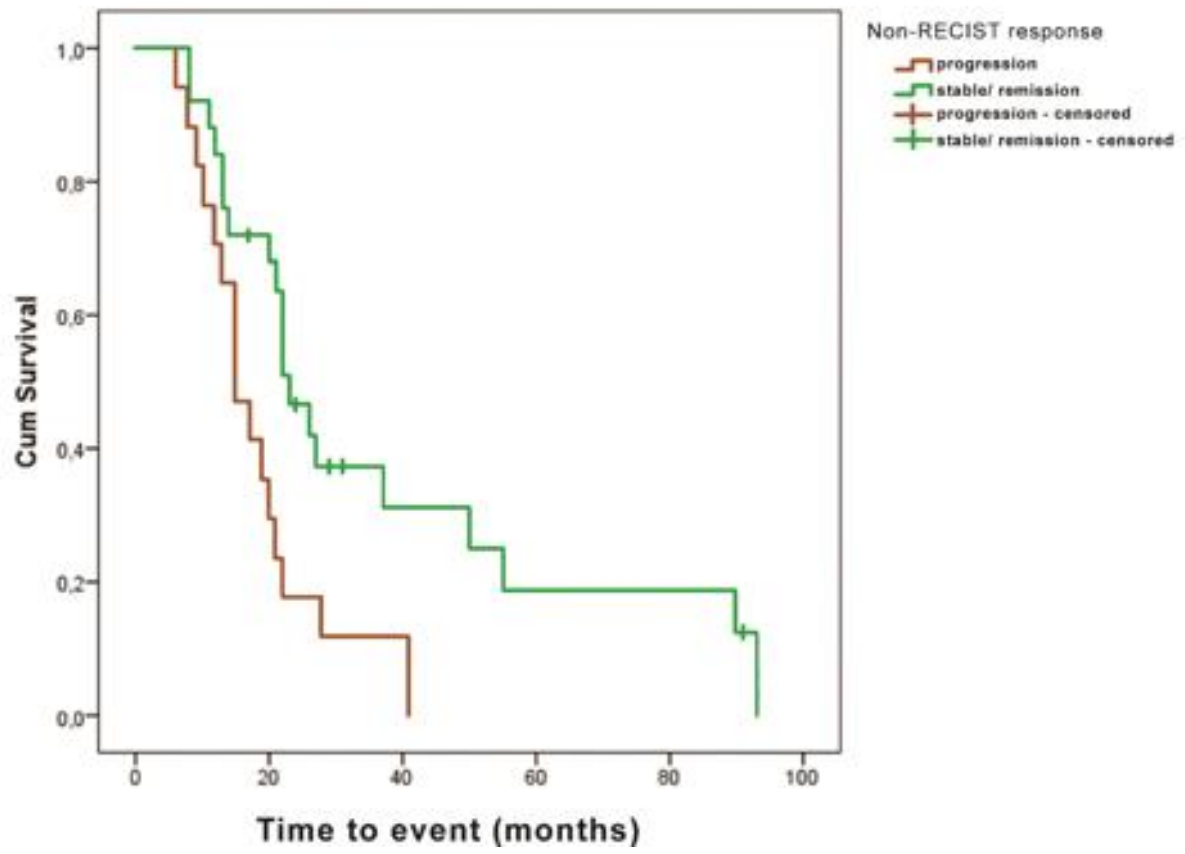

Figure 2. Overall survival Kaplan Meier curves in responding versus non-responding esophagial cancer patients

When analyzed according to response, the differences in OS were significant in both subgroups: 15 months, 95\% CI [7.69-22.30] versus 23 months 95\% CI [17.74-28.25] in SCC patients ( $\mathrm{p}=0.008)$ respectively 15 months, 95\% CI [6.68-23.31] versus 22 months 95\% CI [6.74-37.25] in AC cases $(\mathrm{p}=0.008)$ (Figure 3).
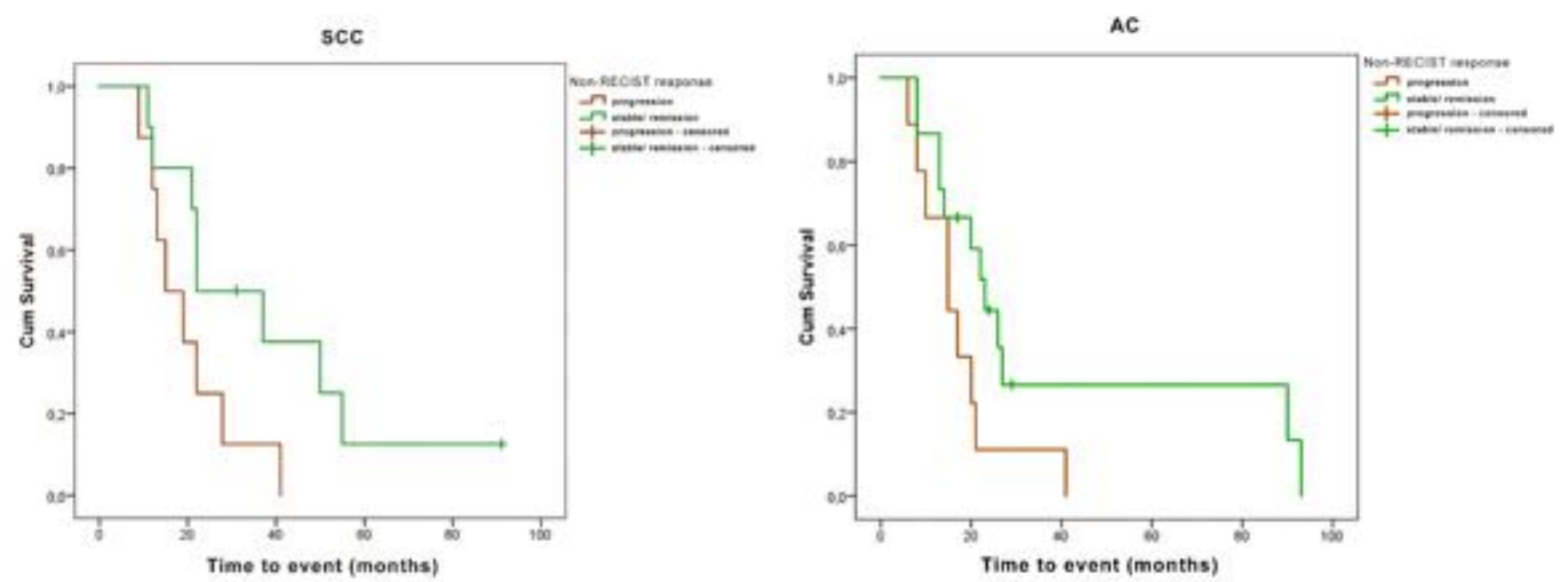

Figure 3. Overall survival Kaplan Meier curves in SCC (squamous carcinoma) esophageal cancer patients (A) and AC (adenocarcinoma) patients (B) according the non-RECIST tumor response

In univariate regression, the median relapse free survival was significantly associated with irradiation dose and the concomitance of chemotherapy to radiotherapy, while in multivariate analysis only the last variable remained significant: HR 0.425, 95\% CI [0.225-0.806], $\mathrm{p}=0.009$ (Tabel 2). 
Table 2. Univariate analysis of association between RFS and tumor or treatment variables

\begin{tabular}{|c|c|c|c|}
\hline Variable & HR & 95\% CI & p \\
\hline $\begin{array}{c}\text { Tumor site } \\
\text { upper third/middle /lower+ JOG }\end{array}$ & 0.863 & $0.610-1.223$ & 0.408 \\
\hline Histopathological type & 0.729 & $0.444-1.196$ & 0.211 \\
\hline TNM stage & 1.071 & $0.790-1.452$ & 0.659 \\
\hline RT $<50$ Gy versus $\geq 50$ Gy & 0.587 & $0.353-0.974$ & $\mathbf{0 . 0 3 9}$ \\
\hline CHT concomitant versus sequential & 0.477 & $0.258-0.881$ & $\mathbf{0 . 0 1 8}$ \\
\hline
\end{tabular}

TNM= tumor, node metastasis stage, $\mathrm{RT}=$ radiotherapy, $\mathrm{CHT}=$ chemotherapy.

\subsection{Discussions}

In the present study response rate doesn't significantly differ between squamous esophageal carcinoma $29.5 \%$ and adenocarcinoma, 39.5\%, $\mathrm{p}=0.475$, although visually it seems higher in the adenocarcinoma subtype. In univariate analysis, the response was directly correlated with field of irradiation and was not influenced by histological subtype or by the type of multimodal treatment, concomitant radio-chemotherapy versus sequential. No differences were recorded neither in relapse free survival nor in overall survival between the two subgroups. Nevertheless, significant differences were recorded inside each histological subgroup if a response was observed or not. The survival without relapse was inversely associated to the dose of irradiation and to the concomitant use of the chemotherapy, whatever the histological type.

In the literature, conflicting results were found. Several retrospective studies found results in favor of much better response in non-metastatic squamous carcinoma upon multimodal treatment.

Thus, in the study regarding 25 patients with squamous and 65 with esophageal adenocarcinoma, after neoadjuvant radio-chemotherapy the response rate was 2.49 higher $p=0.049$. Nevertheless, median OS and PFS were not significantly statistically higher in patients with squamous histology, 60 mo, 95\% CI, [23.7-60] versus 30.8 mo, 95\% CI [20.6-52.3] and 49.4 mo 95\% CI [20.9-60] versus 19.5 mo 95\% CI [13.6-33.7] respectively [12].

A study which specifically analyzed the association between pathological complete response and survival in locally advanced esophageal cancer patients treated by chemo-radiotherapy followed by surgical excision( $\mathrm{N}=103 \mathrm{pts}$ ), of which 49pts displayed histological complete response, found that the relative risk of specific death was $1.6,95 \%$ CI [0.92-2.76] $\mathrm{p}=0.092$ when comparing adenocarcinoma to squamous carcinoma, while the risk for recurrence was $1.973,95 \%$ CI [1.07-3.62], $\mathrm{p}=0.029$. As for patients with pathological complete response, the relative risk for death was 2.006, 95\% [0.684-5.883] in adenocarcinoma versus 3.114, 95\% [0.88-10.95] in squamous carcinoma [13].

In a study of Mariette et al., 98 patients treated with neoadjuvant radio-chemotherapy, followed by surgical intervention, the HR for OS was $1.26,95 \%$ CI [0.86-1.85] $(\mathrm{p}=0.24)$ for patients with adenocarcinoma ( $\mathrm{N}=30 \mathrm{pts})$ versus squamous cell carcinoma ( $\mathrm{N}=67 \mathrm{pts})$ [14].

A better complete histologic response in squamous cell carcinoma cases was also reported by Burmeister et al., 27\% versus 9\% in adenocarcinoma cases $(\mathrm{p}=0.02)$ and HR for PFS $0.47,95 \%$ CI [0.25-0.86] [15].

There are several findings in favor of adenocarcinoma histology. Hence, in a study of 178 patients, 134 cases of adenocarcinoma and 41 cases of squamous cell carcinoma, the neoadjuvant radiochemotherapy led to pathological complete response (ypT0) in $29 \%$ cases, $23 \%$ of adenocarcinoma and $49 \%$ of squamous cell carcinoma ( $\mathrm{p}=0.008)$. Paradoxically, HR for OS was $0.657,95 \%$ CI [0.4950.781 ] in patients with adenocarcinoma versus those with squamous cell carcinoma. 


\section{Conclusions}

With the limitations of a retrospective analysis and a small sample size, the findings of our study regarding tumor response are different from most studies available in literature and show a trend to a better response in adenocarcinoma esophageal cancer after multimodal treatment. These results are probably due to a better patient general performance status, a higher density dose taken during concomitant or sequential chemotherapy, but a lower received median irradiation dose, reflecting rather a high chemosensitivity of adenocarcinoma histology than a better responsiveness to irradiation.

The hypothesis of a better response to radiotherapy of squamous histology and its association with a better survival, as well as a satisfying tolerance to treatment and quality of life remains to be analyzed in a meta-analysis.

Acknowledgments: We would like to Mrs Isabel Grégoire, $\mathrm{PhD}$, Centre Georges François Leclerc for providing the medical writing and editorial assistance and to Mr Sorin S Opris for his graphical assistance in preparing the article.

\section{References}

1.FITZMAURICE, C., AKINYEMIJU, T.F., AL LAMI, F.H., ALAM, T., ALIZADEH-NAVAEI, R., JAMA Oncology 4(11), 2018, p.15

2.AJANI, J.A., D'AMICO, T.A., BENTREM, D.J., CHAO, J., CORVERA, C., DAS, P., Journal of the National Comprehensive Cancer Network 17(7), 2019, p.28

3.LORDICK, F., MARIETTE, C., HAUSTERMANS, K., OBERMANNOVA, R., ARNOLD, D., COMMITTEE, E.G., Annals of oncology : official journal of the European Society for Medical Oncology. 27(suppl 5), 2016, p.43

4.SIEWERT, J.R., STEIN, H.J., FEITH, M., BRUECHER, B.L., BARTELS, H., FINK, U., Annals of surgery, 234(3), 2001 p.7

5.VAN HAGEN, P., HULSHOF, M.C., VAN LANSCHOT, J.J., STEYERBERG, E.W., VAN BERGE, HENEGOUWEN, M.I., WIJNHOVEN, B.P., The New England journal of medicine. 366(22), 2012, p.10

6.XI, M., XU, C., LIAO, Z., HOFSTETTER, W.L., BLUM MURPHY, M., MARU, D.M., Radiotherapy and oncology : journal of the European Society for Therapeutic Radiology and Oncology, 124(2), 2017, p.6

7.OPPEDIJK, V., VAN DER GAAST, A., VAN LANSCHOT, J.J., VAN HAGEN, P., VAN OS, R., VAN RIJ, C.M., Journal of clinical oncology : official journal of the American Society of Clinical Oncology, 32(5), 2017, p.6

8.ROBB, W.B., MESSAGER, M., DAHAN, L., MORNEX, F., MAILLARD, E., D'JOURNO, X.B., The British journal of surgery, $\mathbf{1 0 3}(1), 2016$, p. 8

9.EDGE, S.B., COMPTON, C.C., Annals of surgical oncology, 17(6), 2010, p.3

10.EISENHAUER, E.A., THERASSE, P., BOGAERTS, J., SCHWARTZ, L.H., SARGENT, D., FORD, R., European journal of cancer, 45(2), 2009, p.19

11.https://ctep.cancer.gov/protocolDevelopment/electronic_applications/docs/CTCAE_v4_.

QuickReference_5x7 [cited May 2019]

12.VON DOBELN, G.A., KLEVEBRO, F., JACOBSEN, A.B., JOHANNESSEN, H.O., NIELSEN, N.H., JOHNSEN, G., Diseases of the esophagus: official journal of the International Society for Diseases of the Esophagus, 32(2), 2019, p.10

13.FRANCOUAL, J., LEBRETON, G., BAZILle, C., GAlAIS, M.P., DUPONT, B., ALVES, A., et al. Journal of visceral surgery, 155(5), 2018, p.9

14.MARIETTE, C., DAHAN, L., MORNEX, F., MAILlARD, E., THOMAS, P.A., MEUNIER, B., et al. Journal of clinical oncology : official journal of the American Society of Clinical Oncology, 32(23), 2014, p.6 15.BURMEISTER, B.H., SMITHERS, B.M., GEBSKI, V., FITZGERALD, L., SIMES, R.J., DEVITT, P., et al., The Lancet Oncology, 6(9), 2005, p.9

$\overline{\text { Manuscript received: } 19.02 .2020}$ 